\title{
Does a fluoro-assisted direct anterior approach for total hip arthroplasty pose an excessive risk of radiation exposure to the surgeon?
}

\author{
Yuta Jinnai, Tomonori Baba*, Xu Zhuang, Hiroki Tanabe, Sammy Banno, Taiji Watari, \\ Yasuhiro Homma, and Kazuo Kaneko
}

Department of Orthopaedic Surgery, Juntendo University School of Medicine, 113-0033 Tokyo, Japan

Received 23 December 2019, Accepted 4 February 2020, Published online 18 February 2020

\begin{abstract}
Introduction: Intraoperative fluoroscopy can be easily used because patients are placed in the supine position during total hip arthroplasty via direct anterior approach (DAA-THA) to reduce complications. However, the cumulative level of radiation exposure by intraoperative fluoroscopy increases as the annual number of cases increases, increasing the risk of influencing the health of both the patients and medical workers. The objective of the study was to compare the radiation exposure time of DAA-THA with osteosynthesis and to determine if the level of radiation exposure exceeded safety limits. Material and methods: DAA-THA was performed in 313 patients between January 2016 and July 2018 and 60 patients with proximal femoral fracture were treated with osteosynthesis. The intraoperative fluoroscopy time was retrospectively surveyed and compared between these two groups. A total of eight surgeons operated DAA-THA employing the same procedure using a traction table. A total of nine surgeons operated osteosynthesis and fluoroscopy was appropriately used during reduction and implant insertion. Results: The mean operative time of DAA-THA was $103.3 \mathrm{~min}$ and that of osteosynthesis was $83.3 \mathrm{~min}$, showing a significant difference $(p<0.05)$. The mean intraoperative fluoroscopy time was $0.83 \mathrm{~min}(\mathrm{SD} \pm 0.68)$ in DAA-THA and $8.91 \mathrm{~min}$ $(\mathrm{SD} \pm 8.34)$ in osteosynthesis showing a significant difference $(p<0.05)$. Conclusions: The intraoperative exposure level was significantly lower and the fluoroscopy time was significantly shorter in DAA-THA than in osteosynthesis for proximal femoral fracture. It was clarified that the annual cumulative radiation exposure level in DAA-THA does not exceed the tissue dose limit.
\end{abstract}

Key words: Total hip arthroplasty, direct anterior approach, radiation exposure, fluoroscopy.

\section{Introduction}

Total hip arthroplasty (THA) is an effective surgical method for the reduction of hip joint pain, functional recovery, and improvement of quality of life (QOL) [1,2]. There are various approaches for THA and one of these, the direct anterior approach (DAA), has recently been attracting attention as an intermuscular and inter-innervated area approach [3]. The characteristic of DAA is low-invasiveness and soft tissue can be conserved, so that postoperative recovery is fast and it is associated with a low dislocation rate and reduction of postoperative pain, for which a favorable postoperative outcome can be expected $[4,5]$. However, it has been occasionally reported that the risk of complications is high early after the introduction of DAA for THA, such as failure of component placement and

\footnotetext{
*Corresponding author: tobaba@juntendo.ac.jp
}

femoral fracture, and the presence of a learning curve has been pointed out [6]. One of the measures to reduce these complications is intraoperative fluoroscopy. In DAA, intraoperative fluoroscopy can be easily used because patients are placed in the supine position during surgery [7]. Appropriate use of intraoperative fluoroscopy may improve not only the complicationreducing effect of total hip arthroplasty via direct anterior approach (DAA-THA) but also the postoperative outcome through accurate evaluation of leg length discrepancy and offset [8-10].

The acceptable radiation exposure level of orthopedists is controversial. The use of intraoperative fluoroscopy is essential for orthopedists to perform osteosynthesis for proximal femoral fracture. Generally, the exposure level during osteosynthesis for proximal femoral fracture applied in the same region as THA is higher than that during osteosynthesis in other regions, so that reduction of the exposure level is necessary [11]. 
Thus, we hypothesized that the intraoperative exposure level during DAA-THA is far lower than that during osteosynthesis for proximal femoral fracture. The objective of the study was to compare the radiation exposure time of DAA-THA with osteosynthesis and to determine if the level of radiation exposure exceeded safety limits.

\section{Material and methods}

\section{Patients}

DAA-THA was performed in 313 patients between January 2016 and July 2018. During the same period, 60 patients with proximal femoral fracture were treated with osteosynthesis (neck fractures: 14, trochanteric fractures: 38, subtrochanteric fractures: 8). The intraoperative fluoroscopy time was retrospectively surveyed and compared between these two groups. The study was approved by the Central Ethical Review Board of our institution (entry number 18-219 approved on December 28 , 2018). Patient information including the age, gender, height, weight, body mass index (BMI), and diagnosis were recorded.

\section{Surgery}

A total of eight surgeons operated DAA-THA employing the same procedure using a traction table. A surgeon (T.B.) familiar with DAA supervised surgery in all cases. Intraoperative fluoroscopy was performed in all cases of DAA-THA. The timing of intraoperative fluoroscopy was: (1) final reaming of the acetabular roof, (2) placement of an acetabular cup, (3) insertion of a trial stem, (4) confirmation of leg length discrepancy after temporary reduction, and (5) after the final implant placement. The implant used was cementless in all cases and several screws were added to the acetabular component cup on the judgment of the operator.

A total of nine surgeons operated osteosynthesis and a surgeon (T.W.) familiar with osteosynthesis supervised surgery in all cases. Intraoperative fluoroscopy was used in all cases. A traction table was used in all cases and fluoroscopy was appropriately used during reduction and implant insertion. For the fluoroscopic apparatus, surgical X-ray apparatus OEC 9900 Elite (GE Healthcare Japan, Tokyo, Japan) was used. The surgeons performed surgery wearing a lead apron as a protective clothing.

\section{Measurement of radiation exposure}

For the exposure level of the operators, the data measured by the fluoroscopic apparatus were summed using the area dosimeter display values immediately after surgery. The fluoroscopy time was retrospectively investigated in the irradiation record of the fluoroscopic apparatus. Since the fluoroscopy time was surveyed in this study and the actual radiation dose was unclear, as shown in Figure 1, phantoms were arranged the same as those in actual surgery and the radiation dose was measured in the thyroid region outside the protector, chest inside the protector, and eye region of the operator using a pocket dosimeter, PDM-127B-SZ (Hitachi health care,
Tokyo, Japan), and dosimeter for the lens, DOSIRIS ${ }^{\mathrm{TM}}$ (IRSN, France) [12].

\section{Statistical analysis}

Statistical analysis was performed using IBM SPSS Statistics 25 for Macintosh (SPSS Inc., Chicago, IL, USA). Independent-samples Student's $t$-test was used for continuous variables, and the chi-squared test was used for dichotomous variables. $p<0.05$ was regarded as significant in all analyses.

\section{Results \\ Patient information}

Table 1 shows the patient information. The age, gender, weight, and BMI were significantly different between the two groups, but no significant difference was noted in the height.

\section{Surgical information}

Table 2 shows the surgical information. The mean operative time of DAA-THA was $103.3 \mathrm{~min}$ and that of osteosynthesis was $83.3 \mathrm{~min}$, showing a significant difference $(p<0.05)$. The intraoperative blood losses were $472.9 \mathrm{~mL}$ and $86.0 \mathrm{~mL}$, respectively, being significantly smaller in osteosynthesis. The mean intraoperative fluoroscopy time was $0.83 \mathrm{~min}$ $(\mathrm{SD} \pm 0.68)$ in DAA-THA and $8.91 \mathrm{~min}(\mathrm{SD} \pm 8.34)$ in osteosynthesis (neck fractures: $6.14 \mathrm{~min}$, trochanteric fractures: $7.81 \mathrm{~min}$, subtrochanteric fractures: $18.98 \mathrm{~min}$ ), showing a significant difference $(p<0.05)$. The mean exposure level per one DAA-THA determined using the results of the investigation using phantoms and mean operative time of the surgeries was $11.09 \mu \mathrm{Sv}$ in the thyroid region outside the protector, $0.21 \mu \mathrm{Sv}$ on the chest inside the protector, and $5.55 \mu \mathrm{Sv}$ in the eye region. In osteosynthesis, the mean exposure level was $118.58 \mu \mathrm{Sv}$ in the thyroid region outside the protector, $2.29 \mu \mathrm{Sv}$ on the chest inside the protector, and $59.38 \mu \mathrm{Sv}$ in the eye region.

\section{Discussion}

Accurate implant placement in THA is one of the most important factors to improve the postoperative outcome. It has recently been reported that computed tomography (CT) navigation and simple navigation are useful for accurate implant placement, but these are not generally used due to the cost [7]. In contrast, fluoroscopic apparatus is installed in most facilities capable of performing orthopedic surgery and supported as a useful tool for DAA-THA. Radiograms have been used at medical practice sites since it was discovered by Röntgen in 1895 . After the intraoperative fluoroscopy method spread early in the 1980s, opportunities for its use has been increasing yearly, but the cumulative level of radiation exposure by intraoperative fluoroscopy increases as the annual number of cases increases, increasing the risk of influencing the health of both the patients and medical workers [13]. Operation is performed staying close 


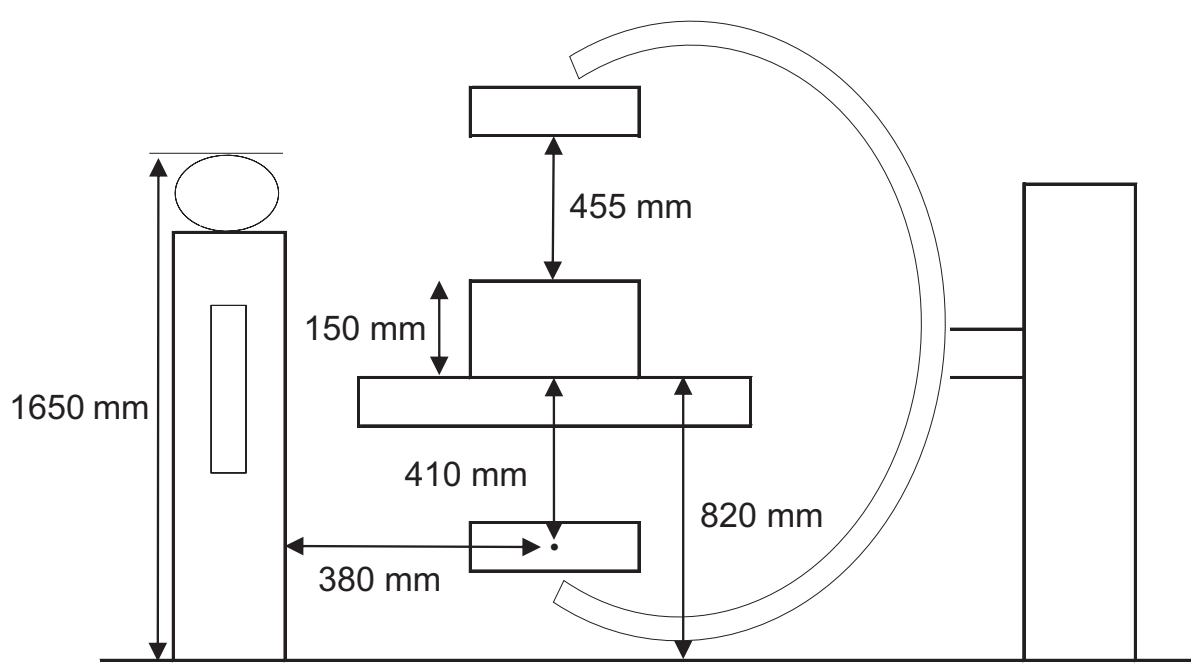

Figure 1. Simulation of DAA-THA by a phantom.

Table 1. Patient characteristics.

\begin{tabular}{lccc}
\hline Measurements & DAA-THA & $\begin{array}{c}\text { Osteosynthesis for proximal } \\
\text { femoral fractures }\end{array}$ & $p$ value \\
\hline Patients (number) & 313 & 60 & $76.2(53-100)$ \\
Age (years) & $67.8(27-92)$ & $25(41.7 \%) / 35(58.3 \%)$ & $<0.05^{*}$ \\
Gender $(\mathrm{male} / \mathrm{female})$ & $69(22.0 \%) / 244(78.0 \%)$ & $154.4(120.0-182.0)$ & $<0.05^{*}$ \\
Height $(\mathrm{cm})$ & $155.4(128.5-187.4)$ & $50.2(34.0-85.0)$ & $<.521$ \\
Weight $(\mathrm{kg})$ & $56.7(29.0-113.5)$ & $21.1(14.4-37.4)$ & \\
BMI $\left(\mathrm{kg} / \mathrm{m}^{2}\right)$ & $23.4(12.1-41.4)$ & & \\
Pre-operative diagnosis & $231(73.8 \%)$ & $14(23.3 \%)$ \\
Osteoarthritis & $2(0.6 \%)$ & $38(63.3 \%)$ \\
Rheumatoid arthritis & $29(9.3 \%)$ & $8(13.3 \%)$ \\
Avascular necrosis of the femoral head & $51(16.3 \%)$ & & \\
Femoral neck fracture & & & \\
Trochanteric fracture & & & \\
Subtrochanteric fracture & & & \\
\hline
\end{tabular}

DAA-THA: total hip arthroplasty via direct anterior approach.

*Significant difference.

Table 2. Operation information.

\begin{tabular}{|c|c|c|c|}
\hline Measurements & DAA-THA & Osteosynthesis for proximal femoral fractures & $\overline{p \text { value }}$ \\
\hline 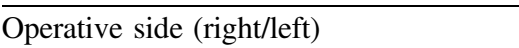 & $167(53.4 \%) / 146(46.6 \%)$ & $22(36.7 \%) / 38(63.3 \%)$ & $<0.05^{*}$ \\
\hline Operation time (min) & $103.3(52-274)$ & $83.3(28-206)$ & $<0.05^{*}$ \\
\hline Blood loss volume (mL) & $472.9(50-2498)$ & $86.0(3-500)$ & $<0.05^{*}$ \\
\hline Radiation time (min) & $0.83(0.1-3.0)$ & $8.91(0.5-39.8)$ & $<0.05^{*}$ \\
\hline Femoral neck fracture & & $6.14(2.8-18.0)$ & \\
\hline Trochanteric fracture & & $7.81(0.5-20.3)$ & \\
\hline Subtrochanteric fracture & & $18.98(3.3-39.8)$ & \\
\hline \multicolumn{4}{|l|}{ Radiation dose $(\mu \mathrm{Sv})$} \\
\hline Thyroid (outside of a lead apron) & $11.09(1.33-39.94)$ & $118.58(6.66-529.87)$ & \\
\hline Sternal notch (inside of a lead apron) & $0.21(0.03-0.77)$ & $2.29(0.13-10.22)$ & \\
\hline Eye & $5.55(0.67-20.00)$ & $59.38(3.33-265.33)$ & \\
\hline
\end{tabular}

DAA-THA: total hip arthroplasty via direct anterior approach.

*Significant difference.

to the radiation source in many cases of fluoroscopic surgery, and radiation exposure is unavoidable for many orthopedists. The objective of this study was to quantify the intraoperative exposure level of surgeons and intraoperative fluoroscopy time and compared these between DAA-THA and osteosynthesis for proximal femoral fracture. 
Table 3. The comparison with previous studies on exposure time.

\begin{tabular}{|c|c|c|c|c|c|c|}
\hline \multicolumn{3}{|l|}{ Measurements } & \multicolumn{2}{|l|}{ Radiation time } & \multicolumn{2}{|l|}{ Radiation dose } \\
\hline Present study & Surgeon & Thyroid (outside of a lead apron) & $0.83(0.1-3.0)$ & $\min$ & $11.09(1.33-39.94)$ & $\mu \mathrm{Sv}$ \\
\hline & & Sternal notch (inside of a lead apron) & & & $0.21(0.03-0.77)$ & $\mu \mathrm{Sv}$ \\
\hline & & Eye & & & $5.55(0.67-20.00)$ & $\mu \mathrm{Sv}$ \\
\hline Curtin et al. [14] & Patient & The individual C-arm fluoroscopy units & $23.74(11.3-61.7)$ & sec & $2.97 \pm 1.63(0.29-9.83)$ & mGy \\
\hline Pomeroy et al. [15] & Surgeon & A helmet-mounted dosimeter & $15.06 \pm 6.73$ & sec & $\begin{array}{c}2.00 \pm 1.3 \\
0.217\end{array}$ & $\begin{array}{l}\text { mGy } \\
\text { mrem }\end{array}$ \\
\hline & Patient & The dosimeter badge placed near & & & 0.0022 & mGy \\
\hline McArthur e & Surgeon & A dosimeter over the lead in the chest area & 0.59 & $\min$ & 10 & mrem \\
\hline McNabb et al. [17] & Surgeon & Fluoroscopic machine & $13.72(6.7-28.7)$ & sec & $178(54-526)$ & mrem \\
\hline
\end{tabular}

Studies on radiation exposure in DAA-THA have been occasionally reported, but the detection method of the radiation exposure level varied and was not uniform (Table 3) [14-17]. Thus, we compared only the intraoperative fluoroscopy time. The intraoperative fluoroscopy time in DAA-THA was 0.23-0.59 min in preceding studies, being shorter than that ( $0.83 \mathrm{~min})$ in our study. This may have been due to compliance with the protocol of the use of intraoperative fluoroscopy standardized in this study, which prolonged the intraoperative fluoroscopy time. The mean intraoperative fluoroscopy time in osteosynthesis for proximal femoral fracture was $0.53-11.8 \mathrm{~min}$ [11, 18, 19], being equivalent to that (8.91 $\mathrm{min}$ ) in our study. Radiation exposure in DAA-THA was far lower than that in routinely performed osteosynthesis for proximal femoral fracture, demonstrating that the risk of unhealthy radiation exposure to the surgeon during DAA-THA is very low. The intraoperative fluoroscopy time was investigated and compared involving a greater number of DAA-THA cases (313) than those (50-157) in the preceding studies, and the total number of operators was 8 , also being greater. In addition, all patients received surgery in the same facility. This indicates that the averaged intraoperative fluoroscopy time was measured along with actual clinical practice, unlike data of surgeries performed by a specified surgeon or performed at multiple facilities. These are differences from preceding studies and novelty can be claimed. Furthermore, to our knowledge, there is no study comparing intraoperative fluoroscopy time of osteosynthesis for proximal femoral fracture and DAA-THA, therefore that point can also claim the novelty of this study.

In the radiation exposure index established by the International Commission on Radiological Protection (ICRP), the annual dose limit for individuals is set for each organ [20]. The mean annual dose limit of 5 years is specified at $20 \mathrm{mSv}$ (100 $\mathrm{mSv}$ in 5 years) with an effective dose per year not exceeding $50 \mathrm{mSv}$. In addition, the tissue dose limit considered able to prevent various tissue damages is specified at $500 \mathrm{mSv}$ for the skin $(500,000 \mu \mathrm{Sv})$ and $150 \mathrm{mSv}$ per year $(150,000 \mu \mathrm{Sv})$ for the eye lens. Since the mean exposure level per one application of DAA-THA was $11.09 \mu \mathrm{Sv}$ in the thyroid region outside the protector and $5.55 \mu \mathrm{Sv}$ in the eye region, to exceed the tissue dose limit, more than about 45,000 and 27,000 surgeries per year are necessary for the skin and eye, respectively. The mean exposure level per one application of DAA-THA was $0.21 \mu \mathrm{Sv}$ on the chest inside the protector, so that more than about 238,000 surgeries are necessary to reach the limit when the operator wears a protector. Thus, DAA-THA is a very safe surgery with regard to radiation exposure. However, the hands operating the surgical field are not protected, being exposed compared with exposure of the trunk wearing protective clothing. Although the exposure level does not exceed the tissue dose limit of the hands and legs, $500 \mathrm{mSv}(500,000 \mu \mathrm{Sv})$, sufficient attention should be paid to exposure of the hands and fingers.

Radiation disorders include acute damage occurring upon exposure to a high dose and late disorder developing several years or decades after exposure to a low dose of radiation. In late disorder, a small dose exposure may induce cancer and cataract $[21,22]$. Development of cataract is of big concern for some surgeons, especially those who use intraoperative fluoroscopy in routine practice (orthopedic trauma surgeons, vascular surgeons, and interventional cardiologists). According to ICRP, the threshold radiation exposure to induce cataract is $0.5 \mathrm{~Gy}(400,000 \mu \mathrm{Sv})$ [23]. In our study, the intraoperative exposure level in the eye region was $5.55 \mu \mathrm{Sv}$, clarifying that the threshold for cataract is reached after performing more than about 72,000 surgeries of DAA-THA even though the operator does not wear an eye protector. So, practically, the risk for cataract is as low as possible. In our additional survey, the exposure level inside the protector was much lower than that outside the protector in each group. It has also been reported that exposure to scattered radiation can be reduced by $90 \%$ or more by wearing a lead apron and thyroid shield [13, 24], suggesting that the shielding effect of the protectors is reliable. It is important to make efforts to reduce the exposure level of operators by wearing a lead apron and thyroid shield in surgery using fluoroscopy. Furthermore, Muller et al. stated that fluoroscopy should not be continuously used during surgery and it should be used only when it is necessary, termed "pulse fluoroscopy" [25]. In DAA-THA, continuous fluoroscopy is unnecessary because fluoroscopy is used to confirm the position of an acetabular cup placement and evaluate leg length discrepancy and offset, and intermittent short-time fluoroscopy may be sufficient.

Regarding limitations, only the fluoroscopy time recorded by the fluoroscopic apparatus was compared because the operators did not use a personal radiation dosimeter. However, sufficient data may have been acquired because the fluoroscopy time recorded by the fluoroscopic apparatus and radiation dose determined by simulation using phantoms were analyzed. 


\section{Conclusions}

The intraoperative exposure level was significantly lower and the fluoroscopy time was significantly shorter in DAATHA than in osteosynthesis for proximal femoral fracture. It was clarified that the annual cumulative radiation exposure level in DAA-THA does not exceed the tissue dose limit.

\section{Conflict of interest}

The authors declare that they have no conflict of interest.

\section{Ethical approval}

Study is approved by our institutional review board.

\section{References}

1. Parker MJ, Gurusamy KS, Azegami S (2010) Arthroplasties (with and without bone cement) for proximal femoral fractures in adults. Cochrane Database Syst Rev 6(6), 1-101.

2. Burgers PT, Van Geene AR, Van den Bekerom MP, Van Lieshout EM, Blom B, Aleem IS, Bhandari M, Poolman RW (2012) Total hip arthroplasty versus hemiarthroplasty for displaced femoral neck fractures in the healthy elderly: A meta-analysis and systematic review of randomized trials. Int Orthop 36(8), 1549-1560.

3. Keggi KJ, Huo MH, Zatorski LE (1993) Anterior approach to total hip replacement: Surgical technique and clinical results of our first one thousand cases using non-cemented prostheses. Yale J Biol Med 66(3), 243-256.

4. Mirza AJ, Lombardi AV Jr., Morris MJ, Berend KR (2014) A mini-anterior approach to the hip for total joint replacement: Optimising results: Improving hip joint replacement outcomes. Bone Joint J 96-B(11 Suppl A), 32-35.

5. Bergin PF, Doppelt JD, Kephart CJ, Benke MT, Graeter JH, Holmes AS, Haleem-Smith H, Tuan RS, Unger AS (2011) Comparison of minimally invasive direct anterior versus posterior total hip arthroplasty based on inflammation and muscle damage markers. J Bone Joint Surg Am 93(15), 1392-1398.

6. Slotkin EM, Patel PD, Suarez JC (2015) Accuracy of fluoroscopic guided acetabular component positioning during direct anterior total hip arthroplasty. J Arthroplasty 30(9 Suppl), 102-106.

7. Matta JM, Shahrdar C, Ferguson T (2005) Single-incision anterior approach for total hip arthroplasty on an orthopaedic table. Clin Orthop Relat Res 441, 115-124.

8. Rathod PA, Bhalla S, Deshmukh AJ, Rodriguez JA (2014) Does fluoroscopy with anterior hip arthroplasty decrease acetabular cup variability compared with a nonguided posterior approach? Clin Orthop Relat Res 472(6), 1877-1885.

9. Homma Y, Baba T, Kobayashi H, Desroches A, Ozaki Y, Ochi H, Matsumoto M, Yuasa T, Kaneko K (2016) Safety in early experience with a direct anterior approach using fluoroscopic guidance with manual leg control for primary total hip arthroplasty: A consecutive one hundred and twenty case series. Int Orthop 40(12), 2487-2494.
10. Kobayashi H, Homma Y, Baba T, Ochi H, Matsumoto M, Yuasa T, Kaneko K (2016) Surgeons changing the approach for total hip arthroplasty from posterior to direct anterior with fluoroscopy should consider potential excessive cup anteversion and flexion implantation of the stem in their early experience. Int Orthop 40(9), 1813-1819.

11. Crawley MT, Rogers AT (2000) Dose-area product measurements in a range of common orthopaedic procedures and their possible use in establishing local diagnostic reference levels. $\mathrm{Br}$ J Radiol 73(871), 740-744.

12. Haga Y, Chida K, Kaga Y, Sota M, Meguro T, Zuguchi M (2017) Occupational eye dose in interventional cardiology procedures. Sci Rep 7(1), 569.

13. Giordano BD, Grauer JN, Miller CP, Morgan TL, Rechtine GR 2nd (2011) Radiation exposure issues in orthopaedics. J Bone Joint Surg Am 93(12), e69(61-10).

14. Curtin BM, Armstrong LC, Bucker BT, Odum SM, Jiranek WA (2016) Patient radiation exposure during fluoro-assisted direct anterior approach total hip arthroplasty. J Arthroplasty 31(6), $1218-1221$.

15. Pomeroy CL, Mason JB, Fehring TK, Masonis JL, Curtin BM (2016) Radiation exposure during fluoro-assisted direct anterior total hip arthroplasty. J Arthroplasty 31(8), 1742-1745.

16. McArthur BA, Schueler BA, Howe BM, Trousdale RT, Taunton MJ (2015) Radiation exposure during fluoroscopic guided direct anterior approach for total hip arthroplasty. J Arthroplasty 30(9), $1565-1568$.

17. McNabb DC, Jennings JM, Levy DL, Miner TM, Yang CC, Kim RH (2017) Direct anterior hip replacement does not pose undue radiation exposure risk to the patient or surgeon. J Bone Joint Surg Am 99(23), 2020-2025.

18. Fuchs M, Schmid A, Eiteljorge T, Modler M, Sturmer KM (1998) Exposure of the surgeon to radiation during surgery. Int Orthop 22(3), 153-156.

19. Roux A, Bronsard N, Blanchet N, de Peretti F (2011) Can fluoroscopy radiation exposure be measured in minimally invasive trauma surgery? Orthop Traumatol Surg Res 97(6), 662-667.

20. Valentin J (2007) The 2007 recommendations of the international commission on radiological protection. ICRP publication 103. Ann ICRP 37(2-4), 1-332.

21. Sanders R, Koval KJ, DiPasquale T, Schmelling G, Stenzler S, Ross E (1993) Exposure of the orthopaedic surgeon to radiation. J Bone Joint Surg Am 75(3), 326-330.

22. Dewey P, Incoll I (1998) Evaluation of thyroid shields for reduction of radiation exposure to orthopaedic surgeons. Aust $\mathrm{N}$ Z J Surg 68(9), 635-636.

23. Authors on behalf of I, Stewart FA, Akleyev AV, Hauer-Jensen M, Hendry JH, Kleiman NJ, Macvittie TJ, Aleman BM, Edgar AB, Mabuchi K, Muirhead CR, Shore RE, Wallace WH (2012) ICRP publication 118: ICRP statement on tissue reactions and early and late effects of radiation in normal tissues and organsthreshold doses for tissue reactions in a radiation protection context. Ann ICRP 41(1-2), 1-322.

24. Le Heron J, Padovani R, Smith I, Czarwinski R (2010) Radiation protection of medical staff. Eur J Radiol 76(1), 20-23.

25. Muller LP, Suffner J, Wenda K, Mohr W, Rommens PM (1998) Radiation exposure to the hands and the thyroid of the surgeon during intramedullary nailing. Injury 29(6), 461-468.

Cite this article as: Jinnai Y, Baba T, Zhuang X, Tanabe H, Banno S, Watari T, Homma Y \& Kaneko K (2020) Does a fluoro-assisted direct anterior approach for total hip arthroplasty pose an excessive risk of radiation exposure to the surgeon? SICOT-J 6, 6 